\title{
Financial Market Dynamics in an Enlarged European Union
}

\author{
Dimitris Kenourgios \\ University of Athens
}

Aristeidis Samitas

University of the Aegean

Nikos Paltalidis

Cass Business School

\begin{abstract}
This paper provides evidence of integration in European equity and bond markets over the period January 2, 1997 to October 1, 2006. Our focus is to examine time-varying correlation dynamics in Euro-area, Central European (CE) and Balkan financial markets, modifying the asymmetric generalized dynamic conditional correlation (AG-DCC) model developed by Cappiello, Engle and Sheppard (Journal of Financial Econometrics, 2006). Using structural breaks, we identify the optimal time decay where financial markets share highest comovement. The results show an increase in the level of dependence during the period of the internet bubble collapse (2000), the Balkan countries start formally discussions to join European Union (2000), the introduction of Euro banknotes and coins (2002) and the entry of CE countries in EU (2004). The CE European and Balkan countries become gradually more integrated with the EMU countries, which is consistent with the interpretation that these countries may be expected to

\footnotetext{
*Corresponding address: Dimitris Kenourgios : Corresponding author: Department of Economics, University of Athens, 5 Stadiou Str., Office 213, 10562 Athens, Greece. e-mail: dkenourg@econ.uoa.gr. Aristeidis Samitas : Department of Business Administration, Business School, University of the Aegean, 8 Michalon Str., 82100 Chios, Greece. Nikos Paltalidis : Faculty of Finance, Cass Business School, City University London, 105 Westbourne Terrace, W2 6QT, Paddington, UK.
} 
join the Euro in the future.

- JEL Classification : C1, F3, G1, G15

- Key Words: European financial markets, time-varying financial dependence, structural breaks, dynamic conditional correlations

\section{Introduction}

The European Union (EU) was originally created by six founding states in 1958 but has grown to its current size of 27 member states. There were six successive enlargements since then, with the largest occurring on May 1, 2004, when 10 new member states joined EU (Estonia, Latvia, Lithuania, Poland, the Czech Republic, Hungary, Slovakia, Slovenia, Malta and Cyprus) and the last one is on January 2007 (Romania and Bulgaria). The process of enlargement is sometimes referred to as European integration. In 1992, the Maastricht treaty was signed and at the same time it is established Economic and Monetary Union (EMU) as a formal objective. The launch of the euro on January 1, 1999 removed exchange rate risks within the euro area, cut transactions costs and further encouraged firms to trade across national borders, thereby providing impetus to trade, investment and employment. On January 1, 2002, Euro notes and coins entered circulation.

One of the important arguments in favour of the existence of the European Economic and Monetary Union (EMU) is that via a higher degree of financial integration it enhances potential output and risk sharing among its participating member states. The integration of Europe's financial markets is an issue of high importance for the Eurosystem. By showing price convergence across a number of financial instruments, the ECB (2005) publication indicators in the Euro-area provide evidence that a significant degree of financial integration has indeed taken place. Financial integration may ultimately support higher and more sustainable economic growth through a variety of channels. Central Eastern and Balkan financial markets integration has vital implications not only for the smooth accession of these economies but for the long-term growth prospects of the EU in general.

The Central Eastern (CE) and Balkan economies have made significant progress towards integration with the world economy over the last decade. The $\mathrm{CE}$ region is expanding more rapidly than the EU average, while the projected annual growth (3\% on average during 2002-2004) outstrips the Euro-zone. Among the Balkan 
economies, the average growth rate of Bulgarian and Romanian economy is $4.8 \%$ and $5.1 \%$, respectively, during the period 2000-2005. Inflation continues to drop to a single-digit annual rate throughout the $\mathrm{CE}$ and Balkan region. The stock and bond markets in these countries have very short history, the liquidity is low and their size remains relatively small, compared to other international markets, but their potential to grow is high (IMF, 2005). In terms of capitalization, turnover, number of traded securities and market return, the CE stock markets move on a growth path during the last six years. Poland, Czech Republic, Hungary and Slovakia are among the top performers (Syriopoulos, 2007). Among the Balkan stock markets, Bulgaria and Romania experience an amazing increase of $777.95 \%$ and $134.44 \%$, respectively, in total market return (local currency) during the period 2000-2005.

The purpose of this paper is to evaluate effects on the return and volatility interdependence among European financial markets for the period 1997-2006. We examine the patterns of correlations on stock and bond markets for six developed countries in the Euro area (Germany, France, Italy, Greece, Spain and Netherlands), six countries which are members of the European Union but have not adopt the Euro currency (Czech Republic, Hungary, Poland, Slovakia Slovenia and Latvia) and two countries which joined EU very recently (Bulgaria and Romania). The inclusion of Bulgaria and Romania is important because this study sheds light on their financial markets integration and evolution.

In this paper, we employ AG-DCC methodology (Cappiello et. al., 2006) which is well suited to examine correlation dynamics among financial markets. This method measures risks dynamically by finding the optimal time decay of covariance information. Using structural breaks, we identify the optimal time decay where European markets share highest dependence (markets are at the same volatility path-comovement). This requires to differentiate our approach from Cappiello et al., (2006). Rather than searching for asymmetries during a financial turmoil, we evaluate the information contained in structural breaks.

Our results provide evidence on structural increase in the level of dependence between all countries both in bond and equity markets, during the period of internet bubble bust (2000), the Balkan countries start formally discussions to join EU (2000), the introduction of the Euro banknotes and coins (2002) and the entry of CE countries in EU (2004). Thus, after the establishment of the EMU (1999), European financial integration is enhanced.

This paper contributes to the plethora of empirical evidence by investigating if 
the dynamics of volatility and correlation in European financial markets increased over the second half of 1990s till 2006. More specifically, this paper contributes to the literature within three ways: (i) adopting a framework which allows asymmetric market movements, we modify the AG-DCC model from asymmetric to symmetric in order to identify the highest time-varying dependence among financial markets; (ii) modelling time-varying dependence to measure risks dynamically employing symmetric specifications for both stock and bond markets; (iii) extending previous research on European financial market integration by incorporating into our analysis the new members of EU ( $\mathrm{CE}$ and Balkan countries).

The structure of the paper is organized as follows: Section II briefly presents the literature review. Section III analyzes methodological issues. Section VI presents the data. The empirical results are reported in Section V. The final section contains the concluding remarks.

\section{Literature Review}

The cointegration methodology developed by Engle and Granger (1987) and Johansen (1988) has given rise to numerous studies of long-run comovements between international stock markets. Empirical investigations into the existence of long-run stock market relations, using univariate and/or multivariate cointegration/ error correction models, traditionally focused on the mature markets of Western Europe, United States and the emerging markets of Asia and Latin America. ${ }^{1}$ For example, Francis and Leachman (1998) and Richards (1995) examine the existence of cointegration relations between the developed European and U.S. markets. Phylaktis (1999) and Manning (2002) investigate the Asian and Pasific-Basin stock markets, while Chen et al. (2002) examine the Latin American markets. The developing stock markets of CE Europe have been investigated to a smaller extent (e.g., Syriopoulos, 2007; Samitas and Kenourgios, 2007). All the above studies provide evidence on the existence of increased equity market integration.

Non-linear cointegration techniques have been developed by Gregory and Hansen (1996), Breitung and Gourieroux (1997), Breitung (2001), and Davies

\footnotetext{
${ }^{1}$ However, the long-run stable equilibrium relationships conjectured by these techniques are not suitable for modeling the dynamic process of stock and bond market integration since these are incomplete and continue to exhibit strong variations over time. However, the long-run stable equilibrium relationships conjectured by these techniques are not suitable for modeling the dynamic process of stock and bond market integration since these are incomplete and continue to exhibit strong variations over time.
} 
(2006). Gregory and Hansen (1996) investigate a non-linear shifting regime regression which takes into account the possibility of instability in long-run relations, allowing for structural breaks. ${ }^{2}$ Adopting the Gregory and Hansen (1996) approach, Voronkova (2004) provide evidence that CE stock markets have become more integrated with global markets.

Kim et al. (2005) examine the influence of the EMU on the dynamic process of stock market integration over the period 1989-2003, using a bivariate EGARCH framework with time-conditional correlations. Using a sample of all preenlargement EU-15 members as well as Japan and US, they find an increase in both regional and global stock market integration and a clear shift in European stock market integration with the introduction of the EMU.

Cappiello et al. (2006), proposing and using the AG-DCC model, support that the introduction of fixed exchange rate regimes led to increased correlation among stock markets and near- perfect correlation among government bond returns within the EMU countries. They also document a structural break in correlation in 1999 using equity indices from European, Australasia and Americas countries. Their approach generalizes the dynamic conditional correlation (DCC) GARCH model of Engle (2002). Similar studies that account for asymmetric effects in conditional covariances are those of Koutmos and Booth (1995), Booth et al. (1997) and Scruggs (1998). However, these studies assume that correlation coefficients are constant over the sample period. ${ }^{3}$

Most recently, researchers have recognized and incorporated an element of timevarying risk premia in their investigation. They found that stock and government bond returns exhibit a modest positive correlation over a long horizon but the relationship is a dynamic one, meaning that the amount of portfolio diversification with a given asset allocation is constantly changing (e.g., Fleming et al. 2003; Scruggs and Glabadanidis, 2003). Finally, Bartram et al. (2007), using a copula function in a GARCH framework, showed that the introduction of Euro eliminates the exchange rate risk within the Euro area. Their findings support that, within the Euro-area, market dependence increased after the introduction of the common

\footnotetext{
${ }^{2}$ However, the Gregory and Hansen approach is possible not to provide robust estimation since it allows for an unknown structural break in the model.

${ }^{3}$ For variants of multivariate GARCH models have been used to accommodate the possibilities of nonnormalities and asymmetries in the variance of returns and their closely related regime switching models, see Bekaert and Harvey (1997), Bekaert et al. (2002), and Baele (2005). However, as with most multivariate GARCH models, these specifications suffer from the curse of dimensionality.
} 
currency, but only for large equity markets. ${ }^{4}$

\section{Methodology}

Following Cappiello et al. (2006), we investigate properties of European equity and bond returns generalizing the DCC-GARCH model of Engle (2002), using two modifications: asset-specific correlation evolution parameters and univariate asymmetrical volatilities.

We let $r_{t}$ be a $\mathrm{k} * 1$ vector of asset returns, which is assumed to be conditionally normal with mean zero and covariance matrix $H_{t}$ :

$$
r_{t} \mid \tilde{h}_{t-1} \sim N\left(0, H_{t}\right)
$$

where $\tilde{h}_{t-1}$ is the time t- 1 information set. All DCC class models use the fact that $H_{t}$ can be decomposed as follows:

$$
H_{t}=D_{t} P_{t} D_{t}
$$

where $D_{t}$ is the $\mathrm{k} * \mathrm{k}$ diagonal matrix of time-varying standard deviations from univariate GARCH models with $\sqrt{h_{i t}}$ on the ith diagonal and $P_{t}$ is the time-varying correlation matrix.

As the DCC model is designed to allow for three stage estimation of the conditional covariance matrix, any univariate GARCH process that is covariance stationary and assumes normally distributed errors (irrespective of the true error distribution) can be used to model the variances (Engle and Sheppard, 2001). In the first stage, volatility estimators are fit for each of the assets, and estimates of hit are obtained. In the second stage, asset returns, transformed by their estimated standard deviations, are used to estimate the intercept parameters of the conditional correlation. Finally, the third stage conditions on the correlation intercept parameters to estimate the coefficients governing the dynamics of correlation.

In the original AG-DCC model, the correlation evolves according to a process with identical news impact and smoothing parameters for all pairs of variables and the first stage contains univariate volatility models. However, in our study we focus

${ }^{4}$ Similar results are reported in Billio and Pelizzon (2003), Savva et al. (2004) and Friedman and Shachmurove (2005). 
in symmetric co-movements identified from structural breaks. Structural breaks often imply changes in the growth rates of the variables.

Our test is able to detect breaks in moments higher than variance. As long as we are interested in modelling the dynamics of the conditional correlation, covariances and volatilities we are concerned about fat tails which if needed we model directly using maximum likelihood. This approach contains three main advantages: (i) higher ability to distinguish between different types of structural shifts; (ii) the procedure utilises the information more efficiently than alternative procedures; (iii) we can identify interpretable coefficients for different types of structural breaks.

Since we have estimated the volatility parameters, the standardised residuals, $\varepsilon_{i, t}$ $=r_{i, t} / \sqrt{h_{i t}}$, are used to estimate the correlation parameters. The evolution of the correlation in the standard DCC model (Engle, 2002) is given by

$$
\begin{gathered}
Q_{t}=(1-a-b) \bar{p}+a \varepsilon_{t-1} \varepsilon_{t-1}^{\prime}+b Q_{t-1} \\
P_{t}=Q_{t}^{*-1} Q_{t} Q_{t}^{*-1}
\end{gathered}
$$

where $\bar{P}=E\left[\varepsilon_{t} \varepsilon_{t}^{\prime}\right]$ and $\alpha$ and $b$ are scalars such that $\alpha+b<1$. $Q_{t}^{*}=\left[q_{i i t}^{*}\right]=\left[\sqrt{q_{i i t}}\right]$ is a diagonal matrix with the square root of the ith diagonal element of $Q_{t}$ on its ith diagonal position. As long as $Q_{t}$ is positive definite, $Q_{t}^{*}$ is a matrix which guarantees $P_{t}=Q_{t}^{*-1} Q_{t} Q_{t}^{*-1}$ is a correlation matrix with ones on the diagonal and every other element $\leq 1$ in absolute value. The model described by equations (3) and (4), however, does not allow for asset-specific news and smoothing parameters or asymmetries.

Cappiello et al. (2006) use the following correlation evolution equation as:

$$
Q_{t}=\left(\bar{P}-A^{\prime} \bar{P} A-B^{\prime} \bar{P} B-G^{\prime} \bar{N} G\right)+A^{\prime} \varepsilon_{t-1} \varepsilon_{t-1}^{\prime} A+G^{\prime} n_{t-1} n_{t-1}^{\prime} G+B^{\prime} Q_{t-1} B
$$

where $A, B$ and $G$ are $\mathrm{k} * \mathrm{k}$ parameter matrices. We modify equation (5) so that parameters are symmetric in the time-decay of structural breaks, as following:

$$
Q_{t}=\left(\bar{P}-S^{\prime} \bar{P} A-B^{\prime} \bar{P} B-G^{\prime} \bar{N} G\right)+S^{\prime} \varepsilon_{t-1} \varepsilon_{t-1}^{\prime} S+G^{\prime} n_{t-1} n_{t-1}^{\prime} G+B^{\prime} Q_{t-1} B
$$

where $S, B$ and $G$ are $\mathrm{k} * \mathrm{k}$ parameter matrices, $n_{t}=I\left[\varepsilon_{t}<0\right]^{\circ} \varepsilon_{t}(I[\bullet]$ is a $\mathrm{k} * 1$ indicator function which takes on value 1 if the argument is true and 0 otherwise, while "。" indicates the Hadamard product) and $\bar{N}=E\left[n_{t} n_{t}^{\prime}\right]$. Equation (6) is the 
symmetric generalized (SG) DCC model based on AG-DCC model on Cappiello et al. (2006).

The symmetric DCC (S-DCC) is obtained as a special case of the SG-DCC and AG-DCC model, if the matrices $A, B$, and $G$ are replaced by scalars and volatility is not asymmetric in the levels (i.e. symmetric). Similarly, the generalised DCC (GDCC) is a special case of the SG-DCC when $G=0$. Our choice of univariate model is a GARCH with one lag of the innovation and one lag of volatility, because according to Cappiello et al. (2006) in the DCC family models using the standard univariate GARCH specifications offer the best performance among large panels.

From equation (6), we set a condition for $Q_{t}$ to be positive definite for all possible realisations so that the intercept, $\bar{P}-S^{\prime} \bar{P} S-B^{\prime} \bar{P} B-G^{\prime} \bar{N} G$, is positive semidefinite and the initial covariance matrix $Q_{0}$ is positive definite. In our study, the scalar symmetric DCC model satisfies this condition when setting $\alpha^{2}+b^{2}<1$.

We allow for structural breaks in both the intercept and the dynamics of the correlation process. Structural breaks in DCC model cause spurious persistence but do not generate spurious asymmetries. We set as $d_{t}$ a dummy variable which takes on value 1 , if $t \geq \tau<T$ and 0 otherwise. Then, we test if there is a structural break in the intercept and in the dynamic correlations using the following model:

$$
\begin{gathered}
Q_{t}=\left(\bar{P}_{1}-A^{\prime} \bar{P}_{1} A-B^{\prime} \bar{P}_{1} B-G^{\prime} \bar{N}_{1} G\right)\left(1-d_{t}\right)+\left(\bar{P}_{2} A^{\prime} \bar{P}_{2} A-B^{\prime} \bar{P}_{2} B-G^{\prime} \bar{N}_{2} G\right) d_{t} \\
+A^{\prime} \varepsilon_{t-1} \varepsilon_{t-1}^{\prime} A+G^{\prime} n_{t-1} n_{t-1}^{\prime} G+B^{\prime} Q_{t-1} B A^{\prime} \varepsilon_{t-1} \varepsilon_{t-1}^{\prime} A \\
+G^{\prime} n_{t-1} n_{t-1}^{\prime} G+B^{\prime} Q_{t-1} B
\end{gathered}
$$

where $\bar{P}_{1}=E\left[\varepsilon_{t} \varepsilon_{t}^{\prime}\right], t<\tau$ and $\bar{P}_{2}=E\left[\varepsilon_{t} \varepsilon_{t}^{\prime}\right], t \geq \tau$ with $\bar{N}_{1}$ and $\bar{N}_{2}$ analogously defined.

Our approach is different from Cappiello et al. (2006) since we test the null hypothesis which implies that there are no structural breaks in our sample. Thus, rather than searching for asymmetries during a financial turmoil, we evaluate the information contained in structural breaks. As long as the presence of structural breaks implies symmetry in a particular time-period (Cappiello et al., 2006), we modify the model from asymmetric to symmetric and search for comovements when financial markets are at the same volatility path.

\section{Data}

The statistical data in the empirical analysis of stock markets consist of the daily 
stock index closing prices in a sample of fourteen European counties. More specifically, the sample is divided into three distinct groups: (i) Stock market indices of six developed stock markets in the Euro area, namely XETRA DAX of Germany, CAC of France, MIBTEL of Italy, IBEX of Spain, AEX All Shares of Netherlands and Athens General Index of Greece; (ii) Stock market indices of six major CE emerging stock markets in the non-Euro area, namely PX of Czech Republic, BUX of Hungary, WIG of Poland, SAX of Slovakia, SBI of Slovenia and OMX RIGA of Latvia; (iii) Stock market indices of two emerging Balkan stock markets in countries which joined the European Union at the begin of 2007, namely SOFIX of Bulgaria and VANGUARD of Romania. These are the main stock indices in our sample markets and represent well-diversified domestic equity portfolios that adequate cover market capitalization.

The empirical analysis of bond markets is conducted using 3-year government bonds (GB) daily closing prices. Given comparable maturities and other relevant characteristics, price movements for government bonds can provide a direct measure of the degree of integration. We prefer to use 3-year GB for two reasons: (i) non-constrained availability of data; (ii) their prices contain short-term as well as long-term information for economic prospects of each country.

We employ daily stock and bond market returns from January 2, 1997 to October 1, 2006, totalling 2,461 observations for each series, and excludes holidays. However, due to constraints on data availability, in the case of Romania the data is from January 2, 2000, while in the case of Bulgaria from October 23, 2000. All returns are continuously compounded. The high frequency data incorporated here include information on short-run market interactions that may be absent in lower frequency data. ${ }^{5}$

The analysis is based on data in local currency terms determined by the availability of daily bond market indices for all countries in the sample, but the findings are basically the same when the data are converted in euros. The stock index prices in local currency depict the domestic market reactions to information from foreign markets from the perspective of the domestic investors (Choudhry, 1994). Expressing the stock price indices in their national currencies restricts also

\footnotetext{
${ }^{5}$ Constraints on data availability do not allow us to use open and close prices, in order to avoid potential non-synchronous trading bias between the examined developed and emerging stock markets. Moreover, the use of weekly data to avoid non-synchronous trading effects may lead to loss of short-run market information (e.g., $\mathrm{Ng}, 2000$ ). As a result, we focus on close prices following prior empirical investigations (e.g., Lee et al., 2004, Bartram et al, 2007).
} 
Table 1. Descriptive Statistics

\begin{tabular}{lcccr}
\hline & Mean & Standard Deviation & Skewness & \multicolumn{1}{c}{ Kurtosis } \\
\hline Germany & $6.73(5.12)$ & $19.75(10.62)$ & $-0.51(0.26)$ & $4.78(3.62)$ \\
France & $9.98(7.14)$ & $20.68(10.75)$ & $-0.52(0.28)$ & $4.92(3.67)$ \\
Spain & $11.35(9.22)$ & $21.36(10.84)$ & $-0.63(0.31)$ & $5.14(3.86)$ \\
Italy & $7.19(5.22)$ & $23.85(10.83)$ & $-0.67(0.32)$ & $5.19(3.89)$ \\
Netherlands & $7.92(6.18)$ & $19.38(10.79)$ & $-0.46(0.24)$ & $4.20(3.44)$ \\
Greece & $12.21(11.31)$ & $25.86(11.24)$ & $-0.72(0.34)$ & $8.00(4.05)$ \\
Czech Rep. & $13.12(12.78)$ & $29.47(16.87)$ & $-0.85(0.41)$ & $11.36(5.72)$ \\
Slovenia & $15.23(14.17)$ & $27.76(13.59)$ & $-0.77(0.35)$ & $9.81(4.53)$ \\
Latvia & $18.21(16.32)$ & $32.90(17.55)$ & $-0.92(0.46)$ & $13.68(6.70)$ \\
Poland & $12.72(11.27)$ & $31.84(17.26)$ & $-0.88(0.41)$ & $12.98(6.27)$ \\
Hungary & $13.18(12.93)$ & $33.62(18.94)$ & $-1.07(0.79)$ & $15.26(8.34)$ \\
Slovakia & $14.41(13.70)$ & $31.75(17.03)$ & $-0.86(0.41)$ & $13.29(6.55)$ \\
Romania & $16.51(15.89)$ & $30.81(16.94)$ & $-0.82(0.40)$ & $12.66(6.48)$ \\
Bulgaria & $17.32(16.28)$ & $34.29(18.73)$ & $-1.02(0.92)$ & $14.95(8.59)$ \\
\hline Desciptive & & &
\end{tabular}

Descriptive statistics for bond returns are in parentheses.

their changes to the movements in the stock prices solely, avoiding distortions induced by numerous devaluations of the exchange rates that have taken place in the $\mathrm{CE}$ and Balkan regions.

\section{Empirical Results}

A range of descriptive statistics for the European bond and stock markets are presented in Table 1. All markets exhibit an average positive return. As for equity returns, all are left skewed and exhibit fat-tails. On the other hand, all bond returns are positively skewed, leptokurtotic and have uniformly lower standard deviations than the equity series.

\section{A. Bond Market Integration}

Table 2 summarises information about the distribution of the conditional correlations for both equity and bond markets over the period 1997-2006. The results show that bond markets are sufficiently strong correlated. Countries in the Euro-area share higher correlation in bond markets. The adoption of a common monetary policy and the consequent irrevocable fixing of exchange rates have led to much higher correlations between bond returns in these countries. CE bond markets share higher conditional correlation with EMU markets rather than with the other CE neighbours. This could be attributed to the growing inflow of foreign 
Table 2. Average Conditional Correlations for Stock and Bond Markets during the Period 1997-2006

\begin{tabular}{|c|c|c|c|}
\hline Country & & Stock markets & Bond markets \\
\hline \multirow[t]{3}{*}{ Germany } & EMU & 0.571 & 0.661 \\
\hline & $\mathrm{CE}$ & 0.431 & 0.410 \\
\hline & Balkans & 0.359 & 0.388 \\
\hline \multirow[t]{3}{*}{ France } & EMU & 0.584 & 0.661 \\
\hline & $\mathrm{CE}$ & 0.403 & 0.393 \\
\hline & Balkans & 0.339 & 0.313 \\
\hline \multirow[t]{3}{*}{ Italy } & EMU & 0.567 & 0.635 \\
\hline & $\mathrm{CE}$ & 0.408 & 0.399 \\
\hline & Balkans & 0.419 & 0.725 \\
\hline \multirow[t]{3}{*}{ Spain } & EMU & 0.584 & 0.641 \\
\hline & $\mathrm{CE}$ & 0.400 & 0.403 \\
\hline & Balkans & 0.307 & 0.321 \\
\hline \multirow[t]{3}{*}{ Netherlands } & EMU & 0.560 & 0.633 \\
\hline & $\mathrm{CE}$ & 0.389 & 0.399 \\
\hline & Balkans & 0.341 & 0.363 \\
\hline \multirow[t]{3}{*}{ Greece } & EMU & 0.521 & 0.576 \\
\hline & $\mathrm{CE}$ & 0.394 & 0.380 \\
\hline & Balkans & 0.425 & 0.379 \\
\hline \multirow[t]{3}{*}{ Czech } & EMU & 0.358 & 0.362 \\
\hline & $\mathrm{CE}$ & 0.333 & 0.288 \\
\hline & Balkans & 0.274 & 0.282 \\
\hline \multirow[t]{3}{*}{ Hungary } & EMU & 0.327 & 0.329 \\
\hline & $\mathrm{CE}$ & 0.210 & 0.225 \\
\hline & Balkans & 0.249 & 0.251 \\
\hline \multirow[t]{3}{*}{ Poland } & EMU & 0.443 & 0.412 \\
\hline & $\mathrm{CE}$ & 0.351 & 0.358 \\
\hline & Balkans & 0.338 & 0.380 \\
\hline \multirow[t]{3}{*}{ Latvia } & EMU & 0.385 & 0.404 \\
\hline & $\mathrm{CE}$ & 0.375 & 0.400 \\
\hline & Balkans & 0.348 & 0.357 \\
\hline \multirow[t]{3}{*}{ Slovakia } & EMU & 0.398 & 0.414 \\
\hline & $\mathrm{CE}$ & 0.343 & 0.375 \\
\hline & Balkans & 0.345 & 0.380 \\
\hline \multirow[t]{3}{*}{ Slovenia } & EMU & 0.513 & 0.537 \\
\hline & $\mathrm{CE}$ & 0.323 & 0.357 \\
\hline & Balkans & 0.343 & 0.362 \\
\hline \multirow[t]{3}{*}{ Bulgaria } & EMU & 0.353 & 0.347 \\
\hline & $\mathrm{CE}$ & 0.369 & 0.289 \\
\hline & Balkans & 0.382 & 0.417 \\
\hline \multirow[t]{3}{*}{ Romania } & EMU & 0.377 & 0.297 \\
\hline & $\mathrm{CE}$ & 0.325 & 0.340 \\
\hline & Balkans & 0.382 & 0.417 \\
\hline
\end{tabular}


Table 3. Conditional Covariances

\begin{tabular}{cc}
\hline EMU Stock Markets & 0.574 \\
EMU Bond Markets & 0.687 \\
CE Stock Markets & 0.526 \\
CE Bond Markets & 0.542 \\
Balkan Stock Markets & 0.518 \\
Balkan Bond Markets & 0.573 \\
\hline
\end{tabular}

All results are significant at $10 \%$ level.

portfolio investments, and the increase of international trading activity in the CE markets. However, it may be related to their short life and the lack of substantial market depth and liquidity. Bulgarian and Romanian bond markets exhibit more regional characteristics since they share higher correlation with each other compared to CE- EMU markets.

Table 3 reports summary statistics for conditional partial covariance into the three groups of countries. Bond markets provide strong evidence of symmetry for each of the three groups of countries. In the EMU bond markets, covariance is the stronger (0.687). Less symmetry is obtained in the Balkan bond markets, where the covariance is only 0.573 .

Using AG-DCC model, we test the null hypothesis of no structural breaks. The test rejects the null hypothesis of no structural breaks. Cointegrated dynamics are represented in our sample with the existence of structural breaks. When countries share strong comovements they are in the same volatility path and their dependence increases. At these points there exist structural shifts in the information contained in the equity and bond markets. Structural shifts create structural breaks with a probability from 0 to 1 . When probability approaches 1 , dependence for the markets become stronger.

In Tables 4 (Panel A) we report the structural breaks for each bond market. In bond markets there are three structural breaks, in 2000, 2002 and 2004, implying increased comovements in these periods. Figure 1 presents the structural breaks in correlation for each bond market. Smooth probabilities imply that there is strong dependence - and hence symmetry - in bond markets for all three structural breaks, with the case of Germany reaching the highest level in 2000 (0.937). This implies that there is a $93 \%$ probability the movement of German bonds to affect other bond markets pushing them in the same volatility path. Strong dependence in bond markets is due to increased monetary policy convergence across EU countries and the macroeconomic (monetary and fiscal) adjustment of the CE and Balkan 

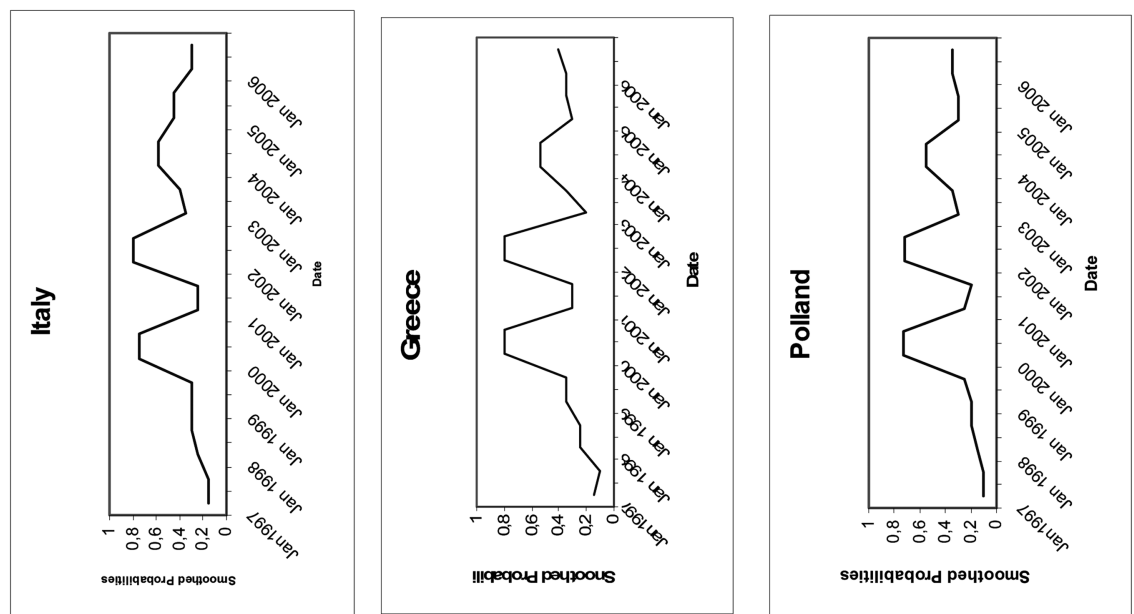

总
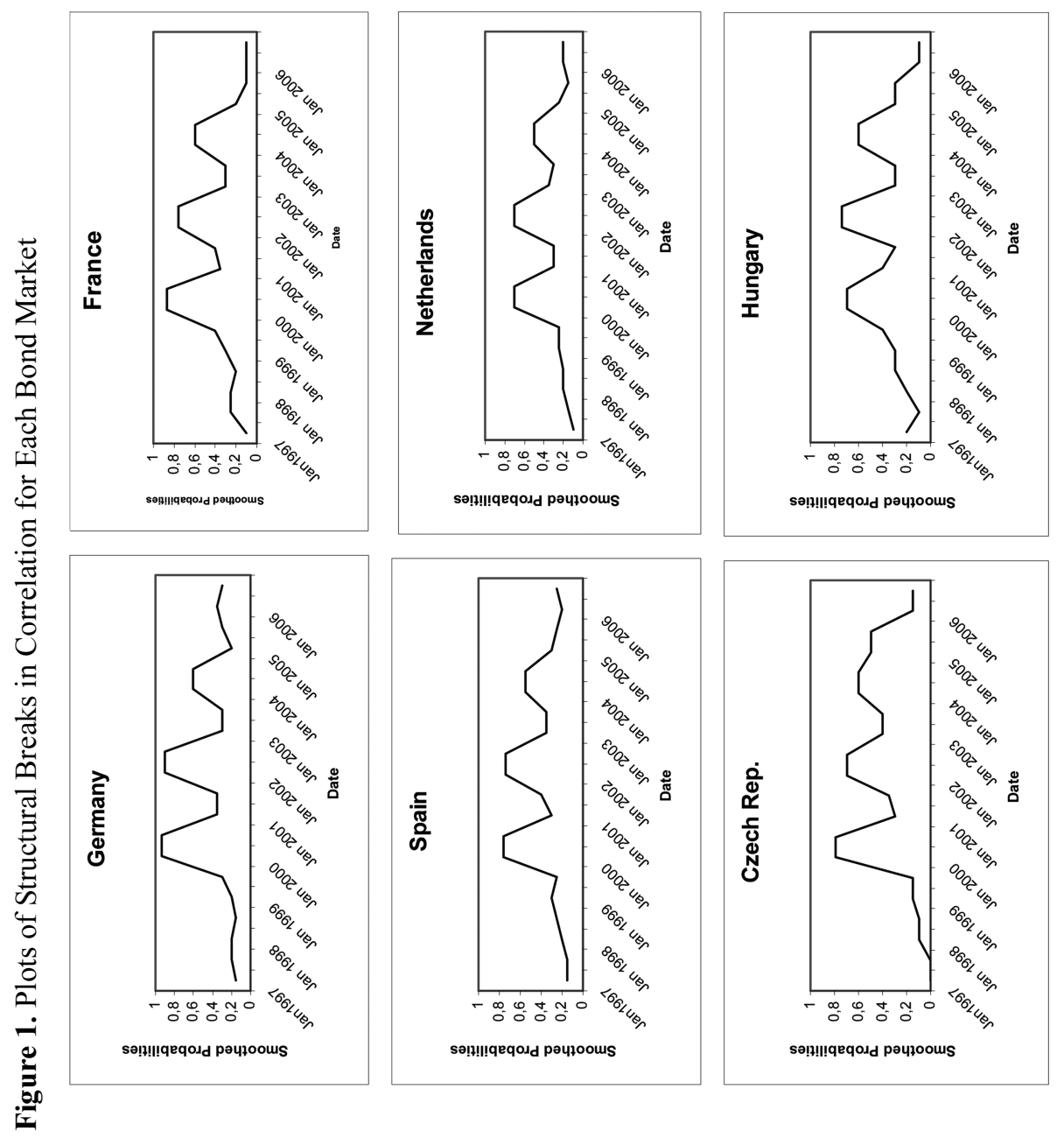


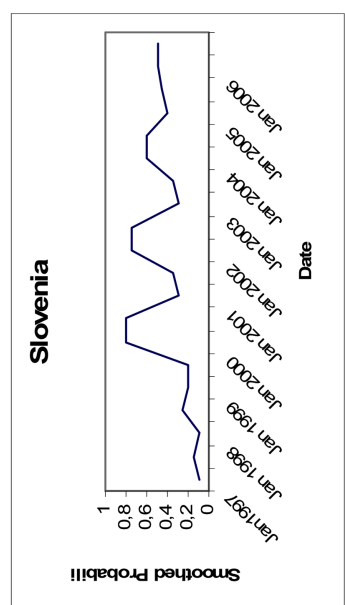

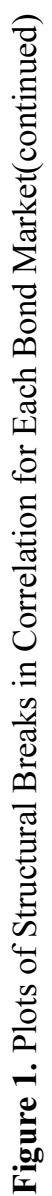
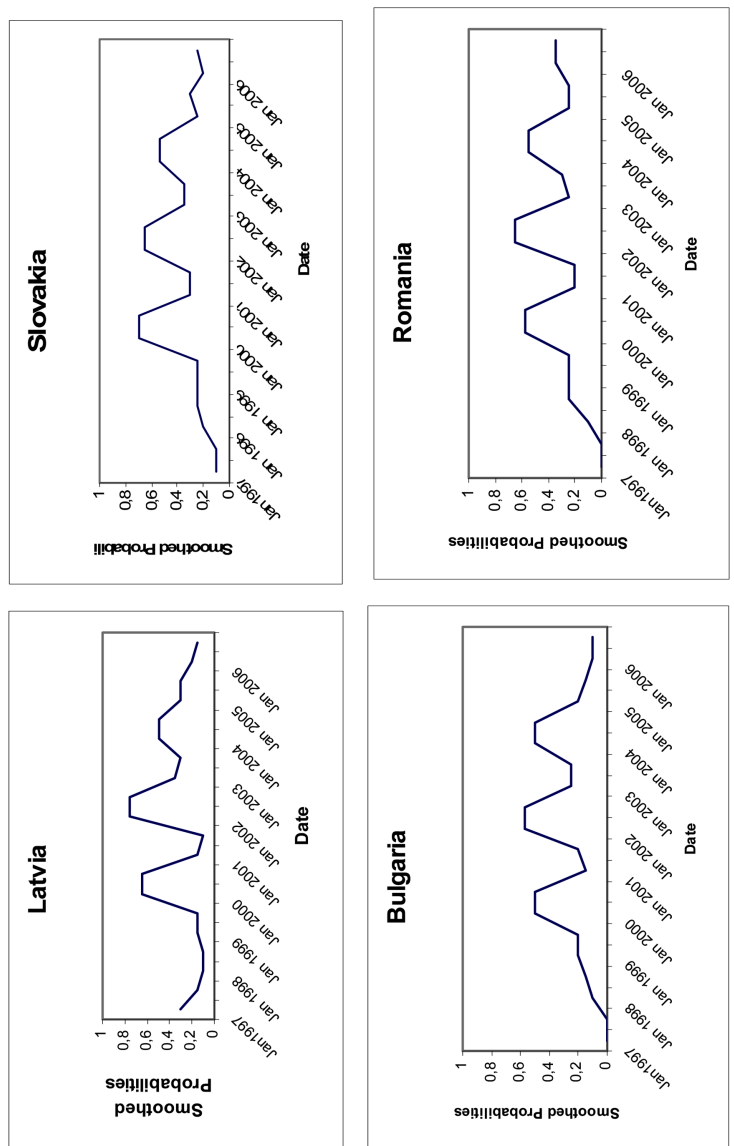
Table 4. Structural Breaks Characteristics

\begin{tabular}{|c|c|c|c|}
\hline \multicolumn{4}{|c|}{ Panel A: Bond Markets } \\
\hline & Str. Break 1 (2000) & Str. Break 2 (2002) & Str. Break 3 (2004) \\
\hline & Probability & Probability & Probability \\
\hline Germany & 0.937 & 0.911 & 0.600 \\
\hline France & 0.873 & 0.761 & 0.638 \\
\hline Italy & 0.771 & 0.825 & 0.580 \\
\hline Spain & 0.762 & 0.743 & 0.559 \\
\hline Netherlands & 0.734 & 0.708 & 0.536 \\
\hline Greece & 0.805 & 0.836 & 0.542 \\
\hline Czech & 0.796 & 0.733 & 0.624 \\
\hline Hungary & 0.713 & 0.744 & 0.629 \\
\hline Poland & 0.738 & 0.722 & 0.578 \\
\hline Slovakia & 0.690 & 0.654 & 0.542 \\
\hline Slovenia & 0.823 & 0.740 & 0.635 \\
\hline Latvia & 0.659 & 0.766 & 0.538 \\
\hline Bulgaria & 0.524 & 0.572 & 0.506 \\
\hline Romania & 0.587 & 0.651 & 0.549 \\
\hline \multicolumn{4}{|c|}{ Panel B: Stock Markets } \\
\hline Germany & 0.904 & 0.893 & 0.578 \\
\hline France & 0.829 & 0.738 & 0.552 \\
\hline Italy & 0.732 & 0.794 & 0.573 \\
\hline ISpain & 0.750 & 0.728 & 0.526 \\
\hline Netherlands & 0.701 & 0.693 & 0.525 \\
\hline Greece & 0.786 & 0.810 & 0.529 \\
\hline Czech & 0.734 & 0.675 & 0.541 \\
\hline Hungary & 0.694 & 0.725 & 0.611 \\
\hline Poland & 0.705 & 0.692 & 0.546 \\
\hline Latvia & 0.604 & 0.682 & 0.512 \\
\hline Slovakia & 0.663 & 0.638 & 0.529 \\
\hline Slovenia & 0.784 & 0.719 & 0.628 \\
\hline Bulgaria & 0.519 & 0.588 & 0.524 \\
\hline Romania & 0.560 & 0.627 & 0.530 \\
\hline
\end{tabular}

economies in order to meet the EU criteria.

The stronger structural breaks in bond markets are observed for EMU countries, followed by CE countries. On the other hand, Bulgarian and Romanian bond markets share weaker comovements with other markets. Higher level of structural breaks in bond markets is reported in 2000 for Germany and France among EMU countries, and Czech Republic and Slovenia among CE countries. On the other hand, higher level of structural breaks is obtained in 2002 for Germany and Greece among EMU countries, and Hungary and Latvia among CE countries. 
Table 5. Average Conditional Correlations for Stock and Bond Markets during Strong Dependence

\begin{tabular}{|c|c|c|c|c|}
\hline & & Str. Break 1(2000) & Str. Break 2(2002) & Str. Break3(2004) \\
\hline \multirow[t]{3}{*}{ Germany } & EMU & $0.728(0.842)$ & $0.706(0.823)$ & $0.637(0.664)$ \\
\hline & $\mathrm{CE}$ & $0.549(0.622)$ & $0.538(0.641)$ & $0.547(0.652)$ \\
\hline & Balkans & $0.518(0.536)$ & $0.527(0.552)$ & $0.539(0.561)$ \\
\hline \multirow[t]{3}{*}{ France } & EMU & $0.740(0.823)$ & $0.652(0.734)$ & $0.672(0.725)$ \\
\hline & $\mathrm{CE}$ & $0.538(0.631)$ & $0.524(0.611)$ & $0.559(0.653)$ \\
\hline & Balkans & $0.507(0.513)$ & $0.510(0.532)$ & $0.546(0.580)$ \\
\hline \multirow[t]{3}{*}{ Italy } & EMU & $0.692(0.786)$ & $0.687(0.699)$ & $0.624(0.677)$ \\
\hline & $\mathrm{CE}$ & $0.515(0.603)$ & $0.521(0.683)$ & $0.532(0.614)$ \\
\hline & Balkans & $0.505(0.516)$ & $0.517(0.548)$ & $0.520(0.559)$ \\
\hline \multirow[t]{3}{*}{ Spain } & EMU & $0.734(0.826)$ & $0.672(0.693)$ & $0.614(0.688)$ \\
\hline & $\mathrm{CE}$ & $0.556(0.619)$ & $0.564(0.627)$ & $0.569(0.642)$ \\
\hline & Balkans & $0.515(0.531)$ & $0.536(0.550)$ & $0.547(0.579)$ \\
\hline \multirow[t]{3}{*}{ Netherlands } & EMU & $0.662(0.756)$ & $0.691(0.738)$ & $0.646(0.694)$ \\
\hline & $\mathrm{CE}$ & $0.539(0.592)$ & $0.558(0.627)$ & $0.563(0.635)$ \\
\hline & Balkans & $0.514(0.526)$ & $0.523(0.538)$ & $0.540(0.552)$ \\
\hline \multirow[t]{3}{*}{ Greece } & EMU & $0.671(0.737)$ & $0.659(0.722)$ & $0.645(0.678)$ \\
\hline & $\mathrm{CE}$ & $0.556(0.591)$ & $0.573(0.639)$ & $0.580(0.642)$ \\
\hline & Balkans & $0.534(0.549)$ & $0.586(0.571)$ & $0.593(0.620)$ \\
\hline \multirow[t]{3}{*}{ Czech } & EMU & $0.642(0.620)$ & $0.628(0.634)$ & $0.611(0.610)$ \\
\hline & $\mathrm{CE}$ & $0.679(0.694)$ & $0.662(0.688)$ & $0.657(0.695)$ \\
\hline & Balkans & $0.520(0.527)$ & $0.534(0.542)$ & $0.581(0.590)$ \\
\hline \multirow[t]{3}{*}{ Slovenia } & EMU & $0.611(0.618)$ & $0.643(0.667)$ & $0.683(0.716)$ \\
\hline & $\mathrm{CE}$ & $0.637(0.645)$ & $0.662(0.689)$ & $0.641(0.693)$ \\
\hline & Balkans & $0.528(0.536)$ & $0.547(0.560)$ & $0.562(0.624)$ \\
\hline \multirow[t]{3}{*}{ Latvia } & EMU & $0.583(0.617)$ & $0.592(0.624)$ & $0.590(0.612)$ \\
\hline & $\mathrm{CE}$ & $0.646(0.673)$ & $0.639(0.658)$ & $0.637(0.644)$ \\
\hline & Balkans & $0.503(0.517)$ & $0.536(0.540)$ & $0.553(0.569)$ \\
\hline \multirow[t]{3}{*}{ Poland } & EMU & $0.621(0.600)$ & $0.592(0.609)$ & $0.607(0.618)$ \\
\hline & $\mathrm{CE}$ & $0.655(0.663)$ & $0.647(0.652)$ & $0.645(0.651)$ \\
\hline & Balkans & $0.539(0.546)$ & $0.552(0.570)$ & $0.568(0.594)$ \\
\hline \multirow[t]{3}{*}{ Hungary } & EMU & $0.589(0.592)$ & $0.610(0.614)$ & $0.613(0.619)$ \\
\hline & $\mathrm{CE}$ & $0.645(0.668)$ & $0.657(0.682)$ & $0.661(0.690)$ \\
\hline & Balkans & $0.522(0.541)$ & $0.543(0.565)$ & $0.574(0.597)$ \\
\hline \multirow[t]{3}{*}{ Slovakia } & EMU & $0.586(0.602)$ & $0.557(0.593)$ & $0.551(0.604)$ \\
\hline & $\mathrm{CE}$ & $0.674(0.649)$ & $0.653(0.642)$ & $0.646(0.655)$ \\
\hline & Balkans & $0.539(0.552)$ & $0.557(0.570)$ & $0.568(0.594)$ \\
\hline \multirow[t]{3}{*}{ Romania } & EMU & $0.502(0.531)$ & $0.528(0.566)$ & $0.574(0.577)$ \\
\hline & $\mathrm{CE}$ & $0.508(0.547)$ & $0.539(0.570)$ & $0.578(0.591)$ \\
\hline & Balkans & $0.742(0.816)$ & $0.761(0.823)$ & $0.737(0.804)$ \\
\hline \multirow[t]{3}{*}{ Bulgaria } & EMU & $0.502(0.510)$ & $0.515(0.522)$ & $0.554(0.576)$ \\
\hline & $\mathrm{CE}$ & $0.516(0.523)$ & $0.527(0.538)$ & $0.560(0.579)$ \\
\hline & Balkans & $0.742(0.816)$ & $0.761(0.823)$ & $0.737(0.804)$ \\
\hline
\end{tabular}

Average conditional correlation for bond returns are in parentheses.

All results are significant at $10 \%$ level. 
Table 5 reports stock and bond markets' conditional correlations for the time decay those structural breaks exist. For the three structural breaks, conditional correlations are clearly increased in bond markets of all sample countries compared with correlations of the period 1997-2006 reported in Table 2. This increased timevarying dependence could be attributed to the internet bubble collapse (2000), the two Balkan countries start formally discussions to join EU (2000), the introduction of Euro banknotes and coins (2002) and the entrance of CE countries in EU (2004).

The higher conditional correlation is found among EMU countries for all three structural breaks. The CE countries exhibit higher dependence with the other countries in all three structural breaks compared to 1997-2006 period (Table 2). However, they tend to display higher correlation with the $\mathrm{CE}$ region rather than with the EMU countries. The CE countries share high trade activity, similar macroeconomic policies, and their economies follow a common path of growth at a regional level. Conditional correlations between the two Balkan countries remain higher compared to CE-EMU countries. Thus, the equity markets in the Balkan region are interdependent and driven, to a grater extent, by regional factors. Finally, among EMU countries, Greece plays a critical and leading role in the Balkan region, sharing the stronger dependence with the two Balkan countries. This could be due to its historical neighboring with these countries and their strong trade and financial linkages.

\section{B. Equity Market Integration}

The results in Table 2 show that equity markets are moderately correlated compared to bond markets. The EMU countries seem to share higher correlation in equity markets. CE equity markets share higher conditional correlation with EMU markets rather than with the other CE counterparts. However, the two Balkan stock markets are stronger correlated with each other compared to CE-EMU markets.

The results in Table 3 for conditional partial covariances into the three stock market groups provide weaker evidence of symmetry compared to bond markets. CE and Balkan stock markets exhibit less symmetry (0.526 and 0.518 , respectively). This could be due to the fact that these equity markets present small capitalization, low trading volume and infrequent trading compared to developed EMU markets.

Table 4 (Panel B) reports the structural breaks for each equity market. Three structural breaks also appear in years 2000, 2002 and 2004. Figure 2 presents the 


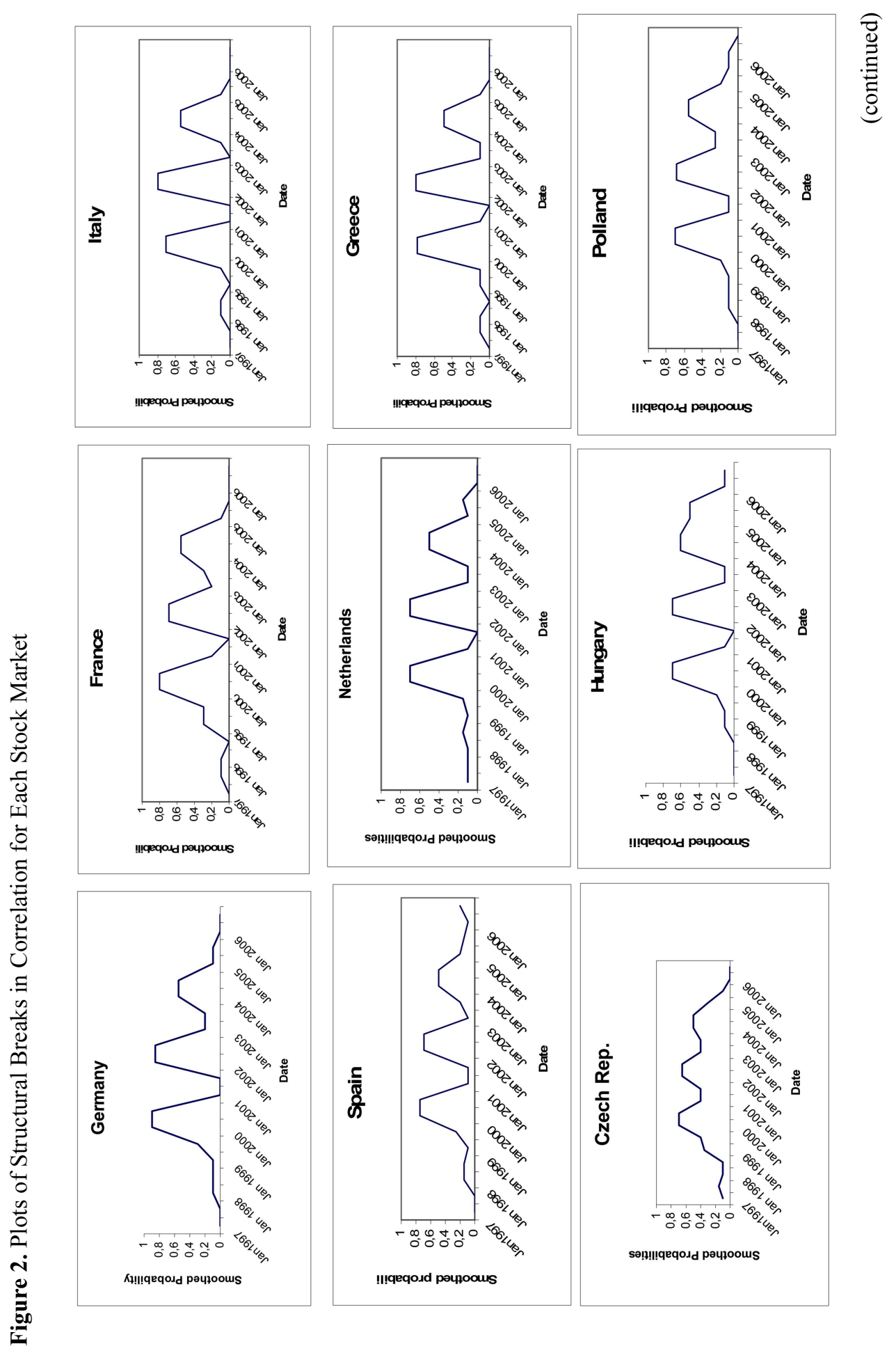



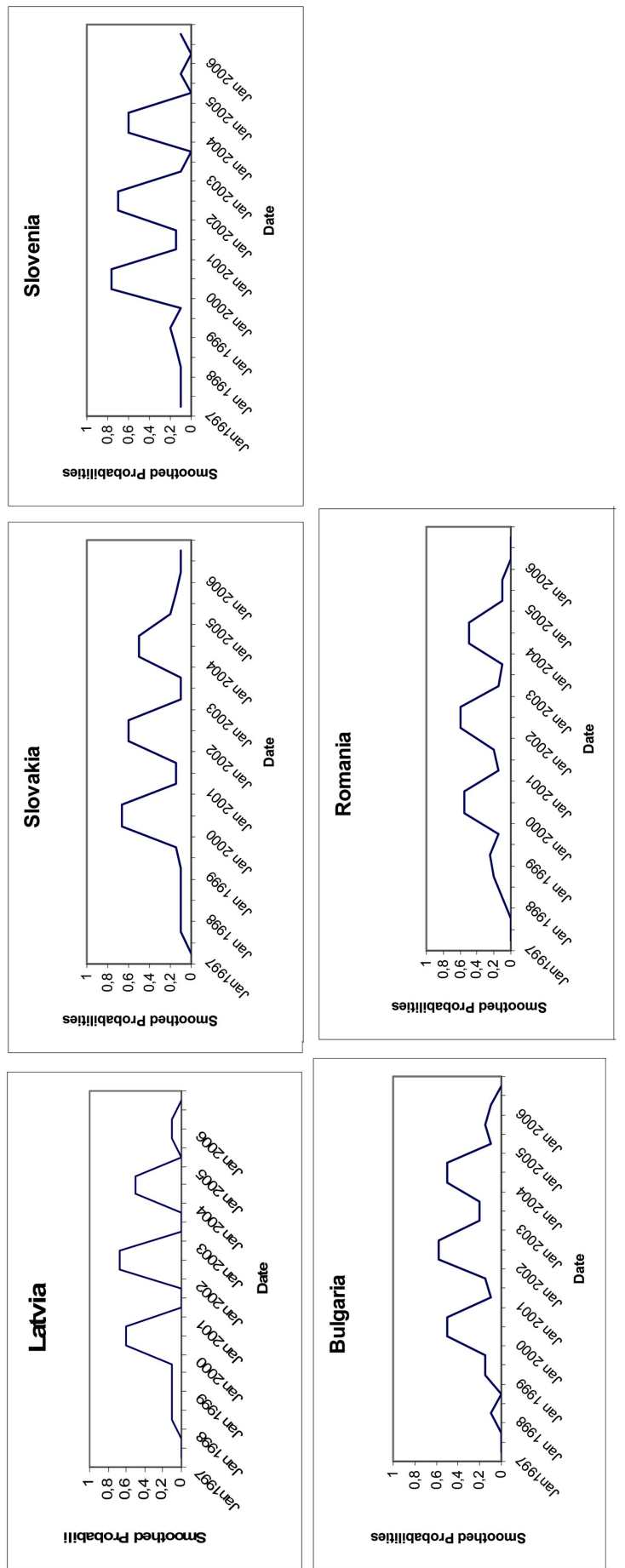
structural breaks in correlation for each equity market. For all three structural breaks, equity markets present weaker dependence and symmetry than bond markets. The highest probability is observed in year 2000 for German stocks (0.904). In structural break 1 (2000), the higher probability is reported for Germany and France among the developed markets, and Czech Republic and Slovenia among CE markets. Moreover, structural break 2 (2002) is stronger for Germany and Greece and Hungary and Slovenia, respectively. Finally, the probabilities observed for structural break 3 (2004) are lower than these in years 2000 and 2002 in stock and bond markets.

Table 5 reports average conditional correlations in stock markets during the period the three structural breaks appeared. The findings are quite similar with those reported for the bond markets. Conditional correlations are clearly higher in all sample stock markets than the correlations of the period 1997-2006, for all structural breaks. Therefore, the results show an increase in the level of equity market dependence during the period of the internet bubble collapse (2000), the Balkan countries start formally discussions to join EU (2000), the introduction of Euro banknotes and coins (2002) and the entry of CE countries in EU (2004).

EMU stock markets share the higher conditional correlation for all three structural breaks. However, CE stock markets tend to display higher linkages with their regional counterparts rather than with the mature stock markets. Balkan stock markets exhibit more regional characteristics, since their conditional correlations are higher compared to CE-EMU stock markets. CE and Balkan stock market integration demands full harmonization of the regulatory environment with the EU standards, increases in the value of institutional investors' assets and improvements in investor protection. Finally, the Greek market plays a key role in the Balkan region among EMU stock markets.

Figure 3 demonstrates plots of the annualised average conditional volatility for the three groups of equity markets. During 2000 and 2002, all stock markets are in a high volatility channel, while in 2004 the volatility path is low. There appear to be strong linkages in equity volatility across the three regions when the three structural breaks exist, evidenced by the tech bust in 2000, the commencement of discussions in order the two Balkan countries to join the EU in 2000, the introduction of Euro banknotes and coins in 2002 and the entrance of CE countries in the EU in 2004. Thus, structural changes in conditional correlations arise from breaks in volatilities.

The finding of increased correlation among the financial markets of our sample 
Figure 3. Plots of the Annualized Conditional Equity Volatility for Three Groups of Countries
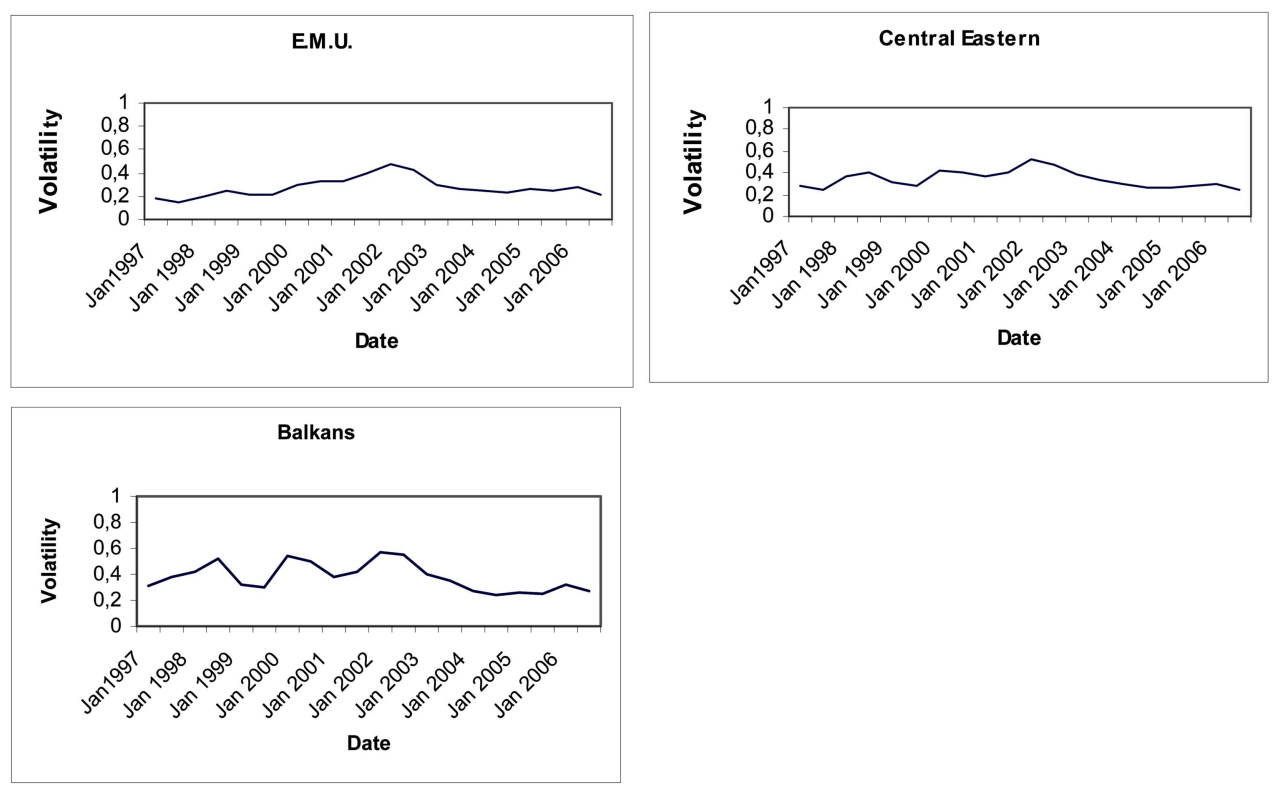

during the tech bust in 2000 supports Cappiello et al. (2006) who provide evidence that correlations tend to rise as markets decline. The rise of technology stocks in the late 1990s led many value-weighted indices to become heavily weighted with tech companies. This let correlation among these indices to move up. When the bubble burst, the large decrease of tech companies' values may have led to a general increase in correlation.

The empirical results largely confirm the hypothesis that countries outside the Euro-area experience a rise in their dependence with EMU countries and vice versa. $\mathrm{CE}$ and Balkan countries are found to exhibit an increase in financial market comovement, which is consistent with the potential expectations of these countries to join the Euro in the future. Our findings for CE stock market integration are consistent with Syriopoulos (2007), Voronkova (2004) and Samitas and Kenourgios (2007). Our results are also in line with related work that provides evidence for increased dependence among major European stock markets after EMU, using vector autoregression, constant and dynamic conditional correlation, EGARCH and structural breaks in copula function (e.g., Billio and Pelizzon, 2003; Savva et al., 2004; Friedman and Shachmurove, 2005; Kim et al., 2005; Bartram et al., 2007). 


\section{Concluding Remarks}

In this paper, we examine the patterns of correlations on financial- stock and bond - markets for six developed countries in the Euro-area (Germany, France, Italy, Greece, Spain and Netherlands), six countries which are members of the European Union but have not adopt the Euro currency (Czech Republic, Hungary, Poland, Slovakia Slovenia and Latvia) and two countries which joined the European Union very recently (Bulgaria and Romania). The sample period is from January 2, 1997 to October 1, 2006.

This study modifies the AG-DCC model developed by Cappiello et al. (2006) evaluating symmetric information in the presence of structural breaks. We use GDCC model with symmetric specification. We find structural breaks in 2000, 2002, and 2004, implying that dependence on European bond and equity markets increased during these three periods. This could be attributed to the tech bust (2000), the two Balkan countries start formally discussions to join EU (2000), the introduction of Euro banknotes and coins (2002) and the entrance of CE countries in the EU (2004). Moreover, structural breaks in bond markets' conditional correlations provide support for stronger dependence and symmetry in specific time horizon.

Also, we document strong comovements in equity market volatility. The results show that all stock markets were in a high volatility path during structural break 1 (2000) and 2 (2002) and in a low volatility path during structural break 3 (2004).

Overall, CE European and Balkan financial markets seem to share strong comovements with their mature counterparts after the introduction of the EMU. For non-Euro European countries, increased trade with Euro-zone and expectations that in future may join Euro seem to increase dependence. Finally, using CE countries as a guide for future market movements, we expect Balkan financial markets to increase their comovement with European markets in the future.

\section{Acknowledgments}

This paper was presented at the European Economic and Finance Society (EEFS) annual conference in Sofia, Bulgaria, May 2007. The authors are grateful to participants and the anonymous referees for their helpful comments. All remaining errors are the authors' responsibility. Funding through a research grant (Kapodistrias) from the University of Athens- Special Account for Research Grants 
is gratefully acknowledged.

Received 25 October 2007, Revised 30 June 2008, Accepted 16 October 2008

\section{References}

Baele, L. (2005), "Volatility Spillover Effects in European Equity Markets", Journal of Financial and Quantitative Analysis, 40, pp. 371-401.

Bartram, S.M., Taylor, S.J., Wang, Y-H. (2007), "The Euro and European Financial Market Dependence", Journal of Banking \& Finance, 31(5), pp. 1461-81.

Bekaert G., Harvey C.R. (1997), "Emerging Equity Market Volatility”, Journal of Financial Econometrics, 43, pp. 29-77.

Bekaert G., Harvey, C.R., Lumsdaine, R.L. (2002), "Dating the Integration of World Equity Markets", Journal of Financial Economics, 65, pp. 203-47.

Billio, M., Pelizzon, L. (2003), "Volatility and Shocks Spillover before and after EMU in European Stock Markets", Working Paper, GRETA, Venice.

Booth, G. G., Martikainen, T., Tse, Y. (1997), "Price and Volatilities Spillovers in Scandinavian Stock Markets”, Journal of International Money and Finance, 21, pp. 811-23.

Breitung, J., Gourieroux, C. (1997), "Rank Test for Unit Roots", Journal of Econometrics, 81, pp. 7-28.

Breitung, J. (2001), "Rank Tests for Nonlinear Cointegration”, Journal of Business and Economic Statistics, 19, pp. 331-40.

Cappiello L., Engle, R.F., Sheppard, K. (2006), “Asymmetric Dynamics in the Correlations of Global Equity and Bond Returns", Journal of Financial Econometrics, 4(4), pp. 537-72.

Chen, G., Firth, M., Rui, O. (2002), "Stock Market Linkages: Evidence from Latin America", Journal of Banking \& Finance, 26, pp. 1113-41.

Davies, A. (2006), "Testing for International Equity Market Integration Using Regime Switching Cointegration Techniques", Review of Financial Economics, 15, pp. 30521.

Engle, R.F. (2002), "Dynamic Conditional Correlation - a Simple Class of Multivariate GARCH Models", Journal of Business and Economic Statistics, 20, pp. 339-50.

Engle, R.F., Granger, C.W. (1987), "Cointegration and Error Correction: Representation, Estimation and Testing", Econometrica, 55, pp. 251-76.

Engle, R.F., Sheppard, K. (2001), "Theoretical and Empirical Properties of Dynamic Conditional Correlation MVGARCH", Working Paper, No. 2001-15, University of California, San Diego.

European Central Bank (2005), Publication Indicators of Financial Integration in the Euro Area, European Central Bank.

Fleming, J., Kirby, C., Ostdiek, B. (2003), "Information and Volume Linkages in the 
Stock, Bond and Money Markets", Journal of Financial Economics, 49, pp. 111-37. Francis, B.B., Leachman, L.L. (1998), "Superexogeneity and the Dynamic Linkages among International Equity Markets", Journal of International Monetary Fund, 17, pp. $475-94$.

Friedman, J., Shachmurove, Y. (2005), "European Stock Market Dynamics before and after the Introduction of the Euro", Working Paper, PIER, University of Pennsylvania.

Gregory, A.W., Hansen, B.E. (1996), "Residual Based Tests for Cointegration in the Models with Regime Shifts", Journal of Econometrics, 70, pp. 99-126.

IMF (2005), Transition: Experience and Policy Issues, in Transition Economies: An IMF Perspective on Progress and Prospects, Chapter III, IMF.

Johansen, S. (1988), "Statistical Analysis of Cointegration Vectors", Journal of Economic Dynamics and Control, 12(2), pp. 231-54.

Kim, S.J., Moshirian, F., Wu, E. (2005), "Dynamic Stock Market Integration Driven by the European Monetary Union: An Empirical Analysis", Journal of Banking \& Finance, 29, pp. 2475-2502.

Koutmos, G., Booth., G.G. (1995), "Asymmetric Volatility Transmission in International Stock Markets", Journal of International Money and Finance, 14, pp. 747-62.

Lee, B.S., Rui, O.M., Wang, S.S. (2004), "Information Transmission between the NASDAQ and Asian Second Board Markets", Journal of Banking and Finance, 28, pp. 1637- 70 .

Manning, N. (2002), "Common Trends and Convergence? South East Asian Equity Markets, 1998 - 1999”, Journal of International Money and Finance, 19, pp. 183202.

Ng, A. (2000), "Volatility Spillover Effects from Japan and the US to the Pacific-Basin", Journal of International Money and Finance, 19, pp. 207-33.

Phylaktis, K. (1999), "Capital Market Integration in the Pacific Basin Region: An Impulse Response Analysis", Journal of International Money and Finance, 18, pp. 267-87.

Richards, A. (1995), "Comovements in National Stock Market Returns: Evidence of Predictability, but not Cointegration", Journal of Monetary Economics, 36, pp. 45579.

Samitas, A., Kenourgios, D. (2007), "Macroeconomic Factors' Influence on "New" European Countries Stock Returns: The Case of Four Transition Economies", International Journal of Financial Services Management, 2(1-2), pp. 34-49.

Savva, C.S., Osborn, D.R., Gill, L. (2004), "Volatility, Spillover Effects and Correlations in U.S. and Major European Markets", Working Paper, University of Manchester.

Scruggs, J.T. (1998), "Resolving the Puzzling Intertemporal Relation between the Market Risk Premium and Conditional Market Variance: a Two-Factor Approach", Journal of Finance, 53, pp. 575-603.

Scruggs, J. T., Glabadanidis, P. (2003), "Risk Premia and the Dynamic Covariance between Stocks and Bond Returns", Journal of Financial and Quantitative Analysis, 38, pp. 295-316. 
Syriopoulos, T. (2007), "Dynamic Linkages between Emerging European and Developed Stock Markets: Has the EMU any Impact?", International Review of Financial Analysis, 16, pp. 41-60.

Voronkova, S. (2004), "Equity Market Integration in Central European Emerging Markets: A Cointegration Analysis with Shifting Regimes", International Review of Financial Analysis, 12, pp. 633-47. 